\title{
O ensino odontológico e os desafios relacionados ao cumprimento dos novos protocolos de biossegu- rança no contexto da pandemia da COVID-19
}

\author{
Suyene de Oliveira Paredes*; Karla Maria Simões Meira*; Paulo Rogério Ferreti Bonan**; Frederico \\ Barbosa de Sousa**; Ana Maria Gondim Valença $^{* *}$ \\ * Doutoranda em Ciências Odontológicas, Programa de Pós- \\ Graduação em Odontologia, Universidade Federal da \\ Paraíba \\ ** Docente, Programa de Pós-Graduação em Odontologia, \\ Universidade Federal da Paraíba
}

Recebido: 17/03/2021. Aprovado: 28/06/2021.

\begin{abstract}
RESUMO
O objetivo deste estudo foi apresentar os desafios relacionados ao cumprimento dos novos protocolos de biossegurança, na perspectiva do retorno das atividades presenciais nas instituições de ensino superior em Odontologia, no cenário da pandemia da COVID-19. Tratou-se de um estudo qualitativo, de caráter exploratório, ancorado na técnica de pesquisa documental. Foram analisados os documentos publicados pelo Ministério da Educação (MEC), Conselho Federal de Odontologia (CFO) e Associação Brasileira de Ensino Odontológico (ABENO). Os documentos foram coletados nos websites das entidades selecionadas. O tratamento dos dados qualitativos foi realizado por meio da análise de conteúdo temática, sendo comparadas qualitativamente as diferentes publicações, identificando-se pontos convergentes, divergentes ou ausentes entre os documentos. Com base na problematização do objeto em questão, foram emitidas sugestões a partir das fragilidades e potencialidades relacionadas à execução das recomendações. Os dados foram distribuídos nas unidades de análise "sala de espera", "clínica" e "laboratório". As principais potencialidades foram relacionadas à diminuição do risco biológico de transmissão de patógenos e à adequação de espaços físicos em ambientes mais ergonômicos de aprendizagem. Quanto às fragilidades, aponta-se o aumento de custos para discentes e instituições e a redução no número de atendimentos. Existem desafios a serem considerados em relação ao cumprimento dos novos protocolos de biossegurança no retorno das atividades práticas nos cursos de Odontologia durante a pandemia da COVID-19.

Descritores: Infecções por Coronavírus. Contenção de Riscos Biológicos. Controle de Infecções Dentárias. Educação em Odontologia.
\end{abstract}




\section{INTRODUÇÃO}

No final do ano de 2019, uma doença causada por um novo tipo de coronavírus surgiu na China ${ }^{1}$. A coronavirus disease (COVID-19), como ficou conhecida, causada pelo vírus SARS-CoV$2^{2}$, tornar-se-ia, então, uma emergência mundial de saúde pública, sendo considerada pela Organização Mundial da Saúde (OMS), em março de 2020, uma pandemia de impacto global ${ }^{3}$. Desde então, um número crescente de casos e de mortes por COVID-19 são relatados globalmente ${ }^{4}$. Medidas de distanciamento social e autoisolamento foram necessárias para reduzir a sua disseminação, trazendo impacto nos diferentes setores da economia ${ }^{5}$, saúde $^{6}$ e educação ${ }^{7}$.

Em relação ao setor da educação, as instituições de ensino, em todos os seus níveis, foram, repentinamente, fechadas em várias localidades do mundo ${ }^{8,9}$. No Brasil, muitas delas ainda permanecem com as aulas presenciais interrompidas ${ }^{10}$, sendo necessária que as entidades de ensino, de forma súbita, adequassem seus métodos, a partir do uso de plataforma digitais, para que o processo de ensino-aprendizagem não fosse totalmente interrompido ${ }^{11-13}$. Houve recomendação do Ministério da Educação para que as atividades presenciais nas instituições de educação superior, integrantes do sistema federal de ensino, sejam retomadas no início de março de 2021, respeitando-se os decretos locais e o cenário epidemiológico vigente à época. Neste documento, é sugerida a adoção do modelo híbrido de ensino (parte remoto e parte presencial) para integralização da carga horária das atividades pedagógicas ${ }^{10}$, o que já vem sendo adotado pela maioria das instituições privadas.

Devido às características dos ambientes odontológicos em geral, em consultórios ou clínicas-escola, o risco de infecção cruzada pode ser alto entre pacientes e cirurgiões-dentistas. Os fluidos orais do paciente, saliva e gotículas de sangue, podem atuar como fontes de contágio para o profissional e para os pacientes. A inalação de aerossóis constitui um risco para quem ocupa ou vai ocupar esses ambientes ${ }^{14}$.

Dessa forma, diante das características inerentes à Odontologia, houve a necessidade de se modificar as medidas preventivas e terapêuticas nesta área. Assim, as recomendações de biossegurança emitidas pelo Ministério da Educação $(\mathrm{MEC})^{15}$, Conselho Federal de Odontologia (CFO) $)^{16-18}$ e Associação Brasileira de Ensino Odontológico (ABENO) ${ }^{19}$ foram revistas com o intuito de nortear as práticas no ambiente de trabalho e ensino, a fim de evitar infecções e disseminação progressiva do vírus e proteger diretamente profissionais, estudantes e pacientes. Nesse contexto, há desafios relacionados à educação em Odontologia, tais como os de garantir a continuidade e qualidade do ensino, de modo a proteger discentes, docentes, pacientes e funcionários $^{12,20,21}$, de avaliar a competência do graduando $^{20}$, além de remodelar a oferta de infraestrutura e reformulação da atividade clínica ${ }^{12}$.

Diante das diretrizes lançadas pelas entidades envolvidas com a prática e o ensino odontológico, e considerando o retorno às atividades presenciais nas instituições de ensino superior em Odontologia, este estudo se propôs a analisar as dificuldades e adaptações atuais relacionadas ao seguimento das novas normas de biossegurança, buscando responder ao seguinte questionamento: quais os desafios enfrentados por discentes, docentes, funcionários e pacientes frente ao cumprimento das normas de biossegurança, no retorno às aulas práticas presenciais dos cursos de graduação em Odontologia durante a pandemia da COVID-19?

\section{METODOLOGIA}

Tratou-se de um estudo qualitativo, de caráter exploratório, ancorado na técnica de pesquisa documental, versando sobre algumas inquietações e reflexões concernentes à atividade 
docente presencial no cenário da pandemia da COVID-19.

Os documentos foram acessados nos websites das entidades selecionadas: MEC, $\mathrm{CFO} \mathrm{e}$ ABENO. Foram consideradas cinco publicações de apenas três entidades, em virtude de terem sido elaboradas por instituições representativas e de referência na política nacional de educação superior (protocolo do $\mathrm{MEC}^{15}$ ), no exercício ético e legal da profissão (manual do CFO - considerado, neste estudo, a junção do manual ${ }^{16}$ e duas atualizações $^{17,18}$, publicadas em $1^{\circ}$. e 22 de junho de 2020), e no interesse das instituições de ensino odontológico do país (consenso da $\mathrm{ABENO}^{19}$ ). Dessa forma, qualquer outro protocolo a ser considerado na área odontológica, emitido por órgãos de gestão em saúde (Secretarias de Saúde) e de ensino (Faculdades de Odontologia), no Brasil, foram excluídos, em virtude dos mesmos, provavelmente, se basearem em um ou mais protocolos emitidos pelas entidades anteriormente citadas.

O tratamento dos dados qualitativos, obtidos a partir do corpus documental, objeto de análise neste estudo (publicações CFO, ABENO e MEC), foi realizado por meio da análise de conteúdo temática. Para melhor apresentação e compreensão dos dados, as unidades de análise (sala de espera, clínica e laboratório) foram distribuídas segundo os diferentes documentos e categorizadas. Dessa forma, comparativamente, identificou-se pontos convergentes, divergentes ou ausentes entre as diferentes publicações. Para o protocolo disponibilizado pelo MEC, foi considerado que a unidade "sala de espera" estava incluída no quesito "áreas comuns" e clínica em "cenários de prática", termos pertencentes a este protocolo.

Em seguida, os autores apresentam reflexões e inquietações sobre o retorno às atividades práticas durante a pandemia de COVID-19, identificando fragilidades e potencialidades relacionadas à execução de tais protocolos no âmbito das instituições de ensino. Com base nesta problematização, foram formuladas sugestões para o cumprimento dessas recomendações. Consideraram-se como potencialidades as melhorias advindas com o cumprimento das novas normas de biossegurança que promovessem mudanças favoráveis nas instituições de ensino. As fragilidades centraram-se nas dificuldades inerentes à execução dos protocolos e as reflexões e sugestões referiram-se às repercussões geradas pelas fragilidades e às tentativas de minimizá-las ou superá-las.

Em síntese, a sistematização dos dados contemplou as seguintes etapas: (1) pré-leitura leitura exploratória dos documentos, definindo-se quais as unidades de análise (com suas categorias e subcategorias) deveriam ser extraídas das publicações selecionadas; (2) leitura seletiva identificou-se a contribuição de cada documento para as unidades de análise estabelecidas; (3) análise descritiva - a partir da leitura seletiva, realizou-se a síntese das informações, descrevendo-se os pontos convergentes e divergentes entre os documentos para as unidades de análise previamente definidas; e (4) análise reflexiva - foram emitidas reflexões/sugestões a partir da identificação das fragilidades e potencialidades relacionadas à execução dos protocolos.

Por se tratar de uma pesquisa documental que analisou publicações de amplo acesso e de domínio público, cujos dados não identificaram indivíduos ou instituições, este estudo não foi submetido ao Comitê de Ética em Pesquisa.

\section{RESULTADOS}

Os dados foram distribuídos em quadros, considerando as três unidades de análise, sendo as categorias decompostas em subcategorias quando apresentassem variedades de especificações.

Em relação à unidade de análise "sala de espera", houve concordância entre as publicações 
ao recomendarem alertas visuais, aferição de temperatura por termômetro infravermelho e a disponibilização de álcool 70\%. No que concerne à utilização de tapetes desinfetantes bactericidas, houve divergência entre os documentos, sendo recomendado apenas pelo CFO. Quanto ao distanciamento entre os assentos, observou-se divergência entre as recomendações do CFO e o consenso da ABENO, especificando um e dois metros, respectivamente (quadro 1).

Quadro 1. Distribuição da unidade de análise "sala de espera" segundo os diferentes documentos

\begin{tabular}{|l|c|c|c|}
\hline \multicolumn{2}{|c|}{ Unidade de Análise "Sala de espera" } \\
\hline Categoria & $\begin{array}{c}\text { Protocolo } \\
\text { MEC }\end{array}$ & $\begin{array}{c}\text { Recomendações } \\
\text { CFO* }\end{array}$ & $\begin{array}{c}\text { Consenso } \\
\text { ABENO }\end{array}$ \\
\hline Entrada - tapete desinfetante bactericida & Não mencionado & Recomendado & Não recomendado \\
\hline Entrada - propés & Não mencionado & Não mencionado & Não mencionado \\
\hline Alertas visuais & Recomendado & Recomendado & Recomendado \\
\hline Oxímetro & Não mencionado & Não mencionado & Recomendado \\
\hline Distanciamento entre assentos & Recomendado & 1 metro & 2 metros \\
\hline Termômetro infravermelho & Recomendado & Recomendado & Recomendado \\
\hline Álcool 70\% & Recomendado & Recomendado & Recomendado \\
\hline
\end{tabular}

Fontes: Ministério da Educação ${ }^{15}$, Conselho Federal de Odontologia ${ }^{16-18}$, Associação Brasileira de Ensino Odontológico ${ }^{19}$.

*Recomendações CFO: considerando em conjunto o manual e as duas atualizações, publicadas em $1^{\circ}$. e 22 de junho de 2020.

Para a unidade de análise "clínica", com foco para categoria EPI (Equipamentos de Proteção Individual), o protocolo do MEC, mesmo mencionando o uso, de forma genérica para todas as áreas, não especifica as subcategorias relacionadas. Percebeu-se concordância na maioria das informações dos documentos do $\mathrm{CFO}$ e da ABENO nesta e nas demais categorias. Entretanto, no quesito paramentação/desparamentação, o consenso da ABENO foi o mais detalhado, sugerindo ambientes distintos para esta finalidade (quadro 2).

Quanto aos laboratórios, houve divergências entre o protocolo do MEC e o consenso da ABENO nas categorias "sistema de aquecimento, ventilação e ar-condicionado" e "distanciamento entre os assentos". Enquanto a ABENO recomenda sistemas de filtragem, ventilação e exaustão de ar, o MEC recomenda a abertura das janelas nos laboratórios. No item EPI, a publicação da ABENO apresentou recomendações detalhadas na maioria das subcategorias. As recomendações do CFO não fazem menção às categorias nesta unidade de análise (quadro 3).

A partir da análise reflexiva sobre os documentos, foram identificadas potencialidades e fragilidades, que são expressas no quadro 4. As principais potencialidades convergiram para manobras passíveis de serem aplicadas e foram relacionadas à diminuição do risco biológico de transmissão de patógenos e à adequação de espaços físicos em ambientes de aprendizagem mais ergonômicos. Quanto às fragilidades, destacaramse o aumento de custos para discentes e instituições, como também, a redução no número de atendimentos.

\section{DISCUSSÃO}

Apesar da impossibilidade de realização de aulas presenciais nos cursos de graduação em Odontologia durante a pandemia da COVID-19, com a adoção de um modelo de aulas remotas, o retorno das atividades práticas presenciais necessita ser planejado e mudanças precisam ser instituídas para que tal retorno aconteça. Nesta perspectiva, este estudo buscou descrever os documentos da ABENO, do MEC e do CFO relacionados à retomada das atividades presenciais de ensino no cenário da pandemia, a fim de sintetizar as informações e apontar as principais 
Quadro 2. Distribuição da unidade de análise "clínica" segundo os diferentes documentos

\begin{tabular}{|c|c|c|c|c|}
\hline \multicolumn{5}{|c|}{ Unidade de Análise "Clínica" } \\
\hline Categoria & $\begin{array}{c}\text { Sub- } \\
\text { categoria }\end{array}$ & $\begin{array}{l}\text { Protocolo } \\
\text { MEC }\end{array}$ & $\begin{array}{c}\text { Recomendações } \\
\text { CFO* }\end{array}$ & $\begin{array}{l}\text { Consenso } \\
\text { ABENO }\end{array}$ \\
\hline $\begin{array}{l}\text { Sistema de } \\
\text { Aquecimento, } \\
\text { Ventilação e Ar- } \\
\text { Condicionado }\end{array}$ & & $\begin{array}{l}\text { Manter os } \\
\text { ambientes } \\
\text { ventilados }\end{array}$ & $\begin{array}{l}\text { Unidade portátil de filtragem } \\
\text { de ar HEPA. } \\
\text { Sistema de ventilação. }\end{array}$ & $\begin{array}{l}\text { Unidade portátil de filtragem de } \\
\text { ar HEPA. } \\
\text { Sistema de ventilação. }\end{array}$ \\
\hline Controle de aerossol & & $\begin{array}{c}\text { Não } \\
\text { mencionado }\end{array}$ & $\begin{array}{l}\text { Sucção de saliva/aspiração } \\
\text { contínua de alta potência. } \\
\text { Evitar canetas de alta e baixa } \\
\text { rotação e aparelhos que } \\
\text { gerem aerossóis. Evitar } \\
\text { seringa tríplice, } \\
\text { especialmente como spray. } \\
\text { Secar com algodão ou gaze. } \\
\text { Atendimento à } 4 \text { mãos. } \\
\text { Utilização precisa de } \\
\text { radiografia intraorais. } \\
\text { Isolamento absoluto. } \\
\end{array}$ & $\begin{array}{l}\text { Barreiras físicas entre as } \\
\text { cadeiras odontológicas. } \\
\text { Atendimento de um único } \\
\text { usuário por turno por estudante. } \\
\text { Sucção de saliva/aspiração } \\
\text { contínua de alta potência. } \\
\text { Evitar canetas de alta e baixa } \\
\text { rotação e aparelhos que gerem } \\
\text { aerossóis. Evitar seringa } \\
\text { tríplice, especialmente como } \\
\text { spray. Atendimento à } 4 \text { mãos. } \\
\text { Uso do Isolamento absoluto. }\end{array}$ \\
\hline $\begin{array}{l}\text { Agentes de } \\
\text { desinfecção }\end{array}$ & & $\begin{array}{c}\text { Não } \\
\text { mencionado }\end{array}$ & $\begin{array}{c}\text { Hipoclorito de Sódio } 1 \% \text {. } \\
\text { Quaternário de amônio e } \\
\text { biguanida. Glucoprotamina. } \\
\text { Álcool } 70 \% \text {. }\end{array}$ & $\begin{array}{c}\text { Álcool } 70 \% \text {. Hipoclorito de } \\
\text { sódio } 1 \% \text {. Ácido peracético } \\
0,2 \% \text { a } 0,5 \% \text {. Quaternários de } \\
\text { amônio } 5 \text { a geração com } \\
\text { biguanida ( } 7 \text { a 9\% } 1: 200)\end{array}$ \\
\hline $\begin{array}{l}\text { Limpeza de ambiente } \\
\text { clínico }\end{array}$ & & $\begin{array}{l}\text { Recomendado } \\
\text { Não } \\
\text { especificado } \\
\end{array}$ & $\begin{array}{l}\text { Álcool } 70 \% \text {. Gluteraldeído } \\
2 \% \text {. Hipoclorito de sódio } 1 \% \text {. } \\
\text { Ácido peracético } 0,001 \text { a } 0,2 \% \text {. }\end{array}$ & $\begin{array}{l}\text { Recomendado } \\
\text { Não especificado }\end{array}$ \\
\hline Distanciamento & & 1,5 metros & $\begin{array}{l}2 \text { metros de espaço entre as } \\
\text { cadeiras odontológicas }\end{array}$ & $\begin{array}{l}2 \text { metros de espaço entre as } \\
\text { cadeiras odontológicas }\end{array}$ \\
\hline $\begin{array}{l}\text { Paramentação/ } \\
\text { desparamentação }\end{array}$ & & $\begin{array}{c}\text { Não } \\
\text { mencionado }\end{array}$ & $\begin{array}{l}\text { Recomendado - Não } \\
\text { especificado }\end{array}$ & $\begin{array}{c}\text { A paramentação e a } \\
\text { desparamentação devem } \\
\text { ocorrer em ambientes distintos }\end{array}$ \\
\hline \multirow[t]{2}{*}{ Avental } & $\mathrm{P} / \mathrm{A} / \mathrm{C}$ & $\begin{array}{l}\text { Recomendado } \\
\text { Não } \\
\text { especificado }\end{array}$ & $\begin{array}{l}\text { Avental descartável } \\
\text { impermeável com mangas } \\
\text { longas, punho de malha ou } \\
\text { elástico, comprimento } 3 / 4 \text {, até } \\
\text { metade da canela e abertura } \\
\text { posterior }\left(\geq 50 \mathrm{~g} / \mathrm{m}^{2}\right)\end{array}$ & $\begin{array}{l}\text { Avental descartável } \\
\text { impermeável com mangas } \\
\text { longas, punho de malha ou } \\
\text { elástico, comprimento } 3 / 4 \text {, até } \\
\text { metade da canela e abertura } \\
\text { posterior }\left(\geq 50 \mathrm{~g} / \mathrm{m}^{2}\right)\end{array}$ \\
\hline & FL & $\begin{array}{l}\text { Recomendado } \\
\text { Não } \\
\text { especificado }\end{array}$ & $\begin{array}{l}\text { Recomendado - não } \\
\text { especificado }\end{array}$ & $\begin{array}{l}\text { Avental impermeável (limpeza } \\
\text { dos pisos)/ avental descartável } \\
\text { (limpeza das superfícies e } \\
\text { descontaminação) }\end{array}$ \\
\hline \multirow[t]{2}{*}{ Gorro } & $\mathrm{P} / \mathrm{A} / \mathrm{C}$ & $\begin{array}{l}\text { Recomendado } \\
\text { Não } \\
\text { especificado }\end{array}$ & $\begin{array}{l}\text { Gorro / touca descartável } \\
\text { impermeável TNT 30g/m2 }\end{array}$ & $\begin{array}{l}\text { Gorro/touca descartável } \\
\text { impermeável TNT 30g/m2 }\end{array}$ \\
\hline & FL & $\begin{array}{l}\text { Recomendado } \\
\text { Não } \\
\text { especificado } \\
\end{array}$ & $\begin{array}{l}\text { Recomendado - não } \\
\text { especificado }\end{array}$ & $\begin{array}{l}\text { Gorro/touca descartável } \\
\text { impermeável TNT 30g/m2 }\end{array}$ \\
\hline \multirow[t]{2}{*}{ Máscara } & $\mathrm{P} / \mathrm{A} / \mathrm{C}$ & $\begin{array}{l}\text { Recomendado } \\
\text { Não } \\
\text { especificado } \\
\end{array}$ & $\begin{array}{l}\text { Máscara cirúrgica tripla } \\
\text { descartável (tipo IIR) }\end{array}$ & $\begin{array}{l}\text { Máscara cirúrgica tripla } \\
\text { descartável (tipo IIR) }\end{array}$ \\
\hline & FL & $\begin{array}{l}\text { Recomendado } \\
\text { Não } \\
\text { especificado }\end{array}$ & $\begin{array}{l}\text { Máscara cirúrgica tripla } \\
\text { descartável (tipo IIR) }\end{array}$ & Não mencionado \\
\hline
\end{tabular}


Quadro 2. Distribuição da unidade de análise "clínica" segundo os diferentes documentos continuação

\begin{tabular}{|c|c|c|c|c|}
\hline Respirador & $\mathrm{P} / \mathrm{A} / \mathrm{C}$ & $\begin{array}{l}\text { Recomendado } \\
\text { Não } \\
\text { especificado }\end{array}$ & $\begin{array}{l}\text { N95/PFF2 ou similar sem } \\
\text { válvula. }\end{array}$ & $\begin{array}{l}\text { N95/PFF2 ou similar sem } \\
\text { válvula }\end{array}$ \\
\hline & FL & $\begin{array}{l}\text { Recomendado } \\
\text { Não } \\
\text { especificado }\end{array}$ & Não mencionado & $\begin{array}{l}\text { Respirador N95/PFF2 ou } \\
\text { similar sem válvula. }\end{array}$ \\
\hline \multirow[t]{2}{*}{ Calçado } & $\mathrm{P} / \mathrm{A} / \mathrm{C}$ & $\begin{array}{l}\text { Recomendado } \\
\text { Não } \\
\text { especificado } \\
\end{array}$ & $\begin{array}{l}\text { Fechados e com solado } \\
\text { antiderrapante. }\end{array}$ & $\begin{array}{l}\text { Fechados e com solado } \\
\text { antiderrapante. }\end{array}$ \\
\hline & FL & $\begin{array}{l}\text { Recomendado } \\
\text { Não } \\
\text { especificado }\end{array}$ & $\begin{array}{l}\text { Botas profissionais, cano } \\
\text { longo, impermeáveis e } \\
\text { antiderrapante. }\end{array}$ & $\begin{array}{c}\text { Botas profissionais, cano longo, } \\
\text { impermeáveis e antiderrapante } \\
\text { (uso exclusivo para limpeza da } \\
\text { clínica) }\end{array}$ \\
\hline \multirow[t]{2}{*}{ Propés } & $\mathrm{P} / \mathrm{A} / \mathrm{C}$ & $\begin{array}{l}\text { Recomendado } \\
\text { Não } \\
\text { especificado } \\
\end{array}$ & Polipropileno 30 gramas. & Não mencionado \\
\hline & FL & $\begin{array}{l}\text { Recomendado } \\
\text { Não } \\
\text { especificado } \\
\end{array}$ & Não mencionado & Não mencionado \\
\hline \multirow[t]{2}{*}{ Luva } & $\mathrm{P} / \mathrm{A} / \mathrm{C}$ & $\begin{array}{l}\text { Recomendado } \\
\text { Não } \\
\text { especificado } \\
\end{array}$ & Vinil / Látex / Cirúrgica & Vinil / Látex / Cirúrgica \\
\hline & FL & $\begin{array}{l}\text { Recomendado } \\
\text { Não } \\
\text { especificado } \\
\end{array}$ & Borracha & Borracha cano longo \\
\hline \multirow[t]{2}{*}{ Sobreluva } & $\mathrm{P} / \mathrm{A} / \mathrm{C}$ & $\begin{array}{l}\text { Recomendado } \\
\text { Não } \\
\text { especificado }\end{array}$ & Recomendado & Recomendado \\
\hline & FL & $\begin{array}{l}\text { Recomendado } \\
\text { Não } \\
\text { especificado } \\
\end{array}$ & Não mencionado & Não mencionado \\
\hline \multirow[t]{2}{*}{ Óculos de proteção } & $\mathrm{P} / \mathrm{A} / \mathrm{C}$ & $\begin{array}{l}\text { Recomendado } \\
\text { Não } \\
\text { especificado }\end{array}$ & $\begin{array}{l}\text { Óculos de proteção com } \\
\text { vedação lateral }\end{array}$ & $\begin{array}{l}\text { Óculos de proteção com } \\
\text { vedação lateral }\end{array}$ \\
\hline & FL & $\begin{array}{l}\text { Recomendado } \\
\text { Não } \\
\text { especificado } \\
\end{array}$ & $\begin{array}{l}\text { Recomendado - não } \\
\text { especificado }\end{array}$ & $\begin{array}{l}\text { Óculos de proteção com } \\
\text { vedação lateral }\end{array}$ \\
\hline \multirow[t]{2}{*}{ Vestimenta } & $\mathrm{P} / \mathrm{A} / \mathrm{C}$ & $\begin{array}{l}\text { Recomendado } \\
\text { Não } \\
\text { especificado }\end{array}$ & Pijama cirúrgico & Pijama cirúrgico \\
\hline & FL & $\begin{array}{l}\text { Recomendado } \\
\text { Não } \\
\text { especificado } \\
\end{array}$ & $\begin{array}{l}\text { Recomendado - não } \\
\text { especificado }\end{array}$ & Pijama cirúrgico \\
\hline \multirow[t]{2}{*}{$\begin{array}{l}\text { Protetor facial } \\
\text { (Faceshield) }\end{array}$} & $\mathrm{P} / \mathrm{A} / \mathrm{C}$ & $\begin{array}{l}\text { Recomendado } \\
\text { Não } \\
\text { especificado } \\
\end{array}$ & Recomendado & Recomendado \\
\hline & FL & $\begin{array}{l}\text { Recomendado } \\
\text { Não } \\
\text { especificado } \\
\end{array}$ & Recomendado & Recomendado \\
\hline
\end{tabular}

Fontes: Ministério da Educação ${ }^{15}$, Conselho Federal de Odontologia ${ }^{16-18}$, Associação Brasileira de Ensino Odontológico ${ }^{19}$.

*Recomendações CFO: considerando em conjunto o manual e as duas atualizações, publicadas em $1^{\circ}$. e 22 de junho de 2020.

P/A/C: Professor /Aluno/ Circulante. FL: Funcionário da Limpeza. 
Quadro 3. Distribuição da unidade de análise "laboratório" segundo os diferentes documentos

\begin{tabular}{|c|c|c|c|c|}
\hline \multicolumn{5}{|c|}{ Unidade de Análise "Laboratório" } \\
\hline Categoria & $\begin{array}{c}\text { Sub- } \\
\text { categoria }\end{array}$ & $\begin{array}{c}\text { Protocolo } \\
\text { MEC }\end{array}$ & $\begin{array}{c}\text { Recomendações } \\
\text { CFO* }\end{array}$ & $\begin{array}{l}\text { Consenso } \\
\text { ABENO } \\
\end{array}$ \\
\hline $\begin{array}{l}\text { Sistema de } \\
\text { Aquecimento, } \\
\text { Ventilação e Ar } \\
\text { Condicionado }\end{array}$ & & $\begin{array}{c}\text { Manter os } \\
\text { ambientes } \\
\text { ventilados } \\
\text { (janelas } \\
\text { abertas) }\end{array}$ & Não mencionado & $\begin{array}{l}\text { Unidade portátil de } \\
\text { filtragem de ar HEPA. } \\
\text { Sistema de ventilação } \\
\text { e/ou exaustão. }\end{array}$ \\
\hline $\begin{array}{l}\text { Distanciamento entre } \\
\text { assentos }\end{array}$ & & 1,5 metros & Não mencionado & 2 metros \\
\hline Avental & $\mathrm{P} / \mathrm{A} / \mathrm{C}$ & $\begin{array}{l}\text { Recomendado } \\
\text { - não } \\
\text { especificado } \\
\end{array}$ & Não mencionado & $\begin{array}{c}\text { Avental descartável } \\
\text { impermeável TNT }\left(30 \mathrm{~g} / \mathrm{m}^{2}\right)\end{array}$ \\
\hline Gorro & $\mathrm{P} / \mathrm{A} / \mathrm{C}$ & $\begin{array}{l}\text { Recomendado } \\
\text { descartável - } \\
\text { não } \\
\text { especificado }\end{array}$ & Não mencionado & $\begin{array}{c}\text { Gorro/touca descartável } \\
\text { impermeável TNT }\left(30 \mathrm{~g} / \mathrm{m}^{2}\right)\end{array}$ \\
\hline Máscara & $\mathrm{P} / \mathrm{A} / \mathrm{C}$ & $\begin{array}{l}\text { Recomendado } \\
\text { descartável - } \\
\text { não } \\
\text { especificado } \\
\end{array}$ & Não mencionado & $\begin{array}{c}\text { Máscara cirúrgica tripla } \\
\text { descartável } \\
\text { (tipo IIR) }\end{array}$ \\
\hline Respirador & $\mathrm{P} / \mathrm{A} / \mathrm{C}$ & $\begin{array}{c}\text { Não } \\
\text { mencionado }\end{array}$ & Não mencionado & $\begin{array}{l}\text { N95/PFF2 ou similar sem } \\
\text { válvula }\end{array}$ \\
\hline Óculos de proteção & $\mathrm{P} / \mathrm{A} / \mathrm{C}$ & $\begin{array}{c}\text { Não } \\
\text { mencionado }\end{array}$ & Não mencionado & $\begin{array}{c}\text { Óculos de proteção com } \\
\text { vedação lateral }\end{array}$ \\
\hline Vestimenta & $\mathrm{P} / \mathrm{A} / \mathrm{C}$ & $\begin{array}{c}\text { Não } \\
\text { mencionado }\end{array}$ & Não mencionado & $\begin{array}{c}\text { Pijama cirúrgico de mangas } \\
\text { curtas }\end{array}$ \\
\hline $\begin{array}{l}\text { Protetor facial (Face } \\
\text { shield) }\end{array}$ & $\mathrm{P} / \mathrm{A} / \mathrm{C}$ & $\begin{array}{c}\text { Não } \\
\text { mencionado }\end{array}$ & Não mencionado & Recomendado \\
\hline
\end{tabular}

Fontes: Ministério da Educação ${ }^{15}$, Conselho Federal de Odontologia ${ }^{16-18}$, Associação Brasileira de Ensino Odontológico ${ }^{19}$.

*Recomendações CFO: considerando em conjunto o manual e as duas atualizações, publicadas em $1^{\circ}$. e 22 de junho de 2020.

P/A/C: Professor /Aluno/ Circulante.

semelhanças e discrepâncias entre eles, além de identificar potencialidades, fragilidades e emitir reflexões à luz dos desafios de se cumprir tais recomendações.

A partir da descrição do corpus documental, observou-se que o consenso publicado pela $\mathrm{ABENO}^{19}$ foi mais completo e minucioso. Constatou-se informações direcionadas ao atendimento mais individualizado nas recomendações formuladas pelo $\mathrm{CFO}$, sendo este mais detalhado na unidade "clínica". Entretanto, ressalta-se que, apesar do $\mathrm{CFO}^{16-18}$ não abordar informações na unidade de análise "laboratório", compreende-se que esta entidade regula o exercício da profissão odontológica e não a formação desses profissionais em nível de graduação. No protocolo do MEC $^{15}$ identificou-se o pouco enfoque para os cenários de práticas dos cursos da área da saúde. Assim, esta publicação direcionou suas orientações, de forma mais abrangente, considerando todos os cursos.

A recomendação de utilização do sistema de ventilação natural foi apontada como uma potencialidade necessária à redução do risco de transmissão de patógenos. Embora o uso de uma unidade portátil de filtragem de ar (High Efficiency Particulate Air Filters - HEPA) tenha sido considerado indispensável durante a realização de procedimentos clínicos que gerem aerossol, por reduzir a contagem de partículas no ambiente e 
Quadro 4. Distribuição das unidades de análise a partir das potencialidades, fragilidades, reflexões e sugestões

\begin{tabular}{|c|c|c|c|}
\hline $\begin{array}{l}\text { Unidade de } \\
\text { Análise/ } \\
\text { Categoria }\end{array}$ & Potencialidade & Fragilidade & Reflexões / Sugestões \\
\hline $\begin{array}{l}\text { Sala de espera } \\
\text { Oxímetro e } \\
\text { termômetro }\end{array}$ & $\begin{array}{l}\text { Manobras simples e de fácil } \\
\text { identificação de sintomas da } \\
\text { COVID-19. Indicativo para a } \\
\text { busca de diagnóstico específico. }\end{array}$ & $\begin{array}{l}\text { Necessidade de funcionário } \\
\text { destinado (e treinado) para } \\
\text { esta função. Manutenção dos } \\
\text { aparelhos. }\end{array}$ & $\begin{array}{c}\text { Sobrecarga de trabalho } \\
\text { para funcionário da sala de } \\
\text { espera. Estas manobras } \\
\text { podem ser realizadas } \\
\text { durante a anamnese. }\end{array}$ \\
\hline $\begin{array}{l}\text { Sala de espera } \\
\text { Distanciamento } \\
\text { entre os assentos }\end{array}$ & $\begin{array}{l}\text { Assegura maior distanciamento } \\
\text { físico entre os pacientes. }\end{array}$ & $\begin{array}{l}\text { Estrutura física pode não } \\
\text { comportar o distanciamento } \\
\text { necessário. Alerta-se para a } \\
\text { redução do número de } \\
\text { pacientes marcados por turno. }\end{array}$ & $\begin{array}{l}\text { Aponta-se para aumento da } \\
\text { demanda reprimida e } \\
\text { redução no quantitativo de } \\
\text { procedimentos realizados. }\end{array}$ \\
\hline $\begin{array}{l}\text { Clínica } \\
\text { Sistema de } \\
\text { ventilação }\end{array}$ & $\begin{array}{l}\text { A adaptação diminuirá o risco } \\
\text { biológico de transmissão de } \\
\text { patógenos por aerossol. }\end{array}$ & $\begin{array}{c}\text { Aumento de custo para a } \\
\text { IES. Necessidade de se } \\
\text { respeitar maiores intervalos } \\
\text { de tempo para uso da clínica } \\
\text { (rotatividade). }\end{array}$ & $\begin{array}{c}\text { A abertura de janelas } \\
\text { poderá ser uma solução } \\
\text { momentânea até que os } \\
\text { exaustores sejam } \\
\text { adquiridos. }\end{array}$ \\
\hline $\begin{array}{l}\text { Clínica } \\
\text { Controle de } \\
\text { aerossol }\end{array}$ & $\begin{array}{c}\text { Evitar uso de aparelhos } \\
\text { rotatórios e geradores de spray, } \\
\text { reduz o risco de contaminação } \\
\text { pelo SARS-Cov-2 e outros } \\
\text { patógenos. }\end{array}$ & $\begin{array}{c}\text { Evitar uso de rotatórios e } \\
\text { geradores de spray repercutirá } \\
\text { na não execução de } \\
\text { procedimentos das técnicas } \\
\text { operatórias de diversas } \\
\text { especialidades. Redução no } \\
\text { fluxo de paciente. Aumento } \\
\text { do tempo para a realização de } \\
\text { procedimentos com } \\
\text { instrumentos manuais. }\end{array}$ & $\begin{array}{l}\text { Comprometimento no } \\
\text { aprendizado técnico } \\
\text { manual. } \\
\text { Sugere-se que mais de um } \\
\text { procedimento seja } \\
\text { realizado no mesmo } \\
\text { paciente. }\end{array}$ \\
\hline $\begin{array}{l}\text { Clínica } \\
\text { Distanciamento } \\
\text { entre as cadeiras } \\
\text { odontológicas }\end{array}$ & $\begin{array}{c}\text { Reforma estrutural para } \\
\text { ampliação de espaço físico, } \\
\text { proporcionará ambiente de } \\
\text { atendimento ergonômico, } \\
\text { redução do risco biológico e } \\
\text { maior privacidade ao paciente. }\end{array}$ & $\begin{array}{c}\text { Reformas estruturais } \\
\text { repercutirão em aumento de } \\
\text { custos para a IES. Estrutura } \\
\text { física pode não comportar o } \\
\text { distanciamento necessário, } \\
\text { reduzindo o número de } \\
\text { alunos e pacientes em } \\
\text { atendimento. }\end{array}$ & $\begin{array}{l}\text { Na impossibilidade de } \\
\text { reforma estrutural para } \\
\text { ampliação de espaço físico, } \\
\text { provavelmente, haverá } \\
\text { isolamento das unidades de } \\
\text { atendimento nas clínicas. }\end{array}$ \\
\hline $\begin{array}{l}\text { Clínica } \\
\text { EPI }\end{array}$ & $\begin{array}{c}\text { Além da proteção contra o } \\
\text { SARS-Cov-2, o cumprimento } \\
\text { no uso dos novos EPI } \\
\text { promoverá maior proteção } \\
\text { contra acidentes ocupacionais e } \\
\text { patógenos que causam outras } \\
\text { infecções. }\end{array}$ & $\begin{array}{l}\text { Aumento de custo para } \\
\text { instituições e alunos } \\
\text { Aumento da quantidade do } \\
\text { lixo biológico Dificuldade } \\
\text { em realizar procedimentos } \\
\text { estéticos com faceshield. }\end{array}$ & $\begin{array}{l}\text { Capotes plásticos permitem } \\
\text { a sua reutilização por meio } \\
\text { da desinfeçãa. Dar } \\
\text { preferência à faceshield } \\
\text { anatômica (menor } \\
\text { distorção visual). }\end{array}$ \\
\hline $\begin{array}{l}\text { Laboratório } \\
\text { Distanciamento } \\
\text { entre os assentos }\end{array}$ & $\begin{array}{l}\text { Reforma estrutural para } \\
\text { ampliação de espaço físico } \\
\text { proporcionará ambiente de } \\
\text { aprendizado mais ergonômico e } \\
\text { menor risco de acidente } \\
\text { ocupacional. }\end{array}$ & $\begin{array}{l}\text { Reformas estruturais } \\
\text { repercutirão em aumento de } \\
\text { custos para a IES. Estrutura } \\
\text { física pode não comportar o } \\
\text { distanciamento necessário. }\end{array}$ & $\begin{array}{l}\text { Na impossibilidade de } \\
\text { reforma estrutural para } \\
\text { ampliação de espaço físico, } \\
\text { provavelmente, haverá } \\
\text { isolamento das bancadas. }\end{array}$ \\
\hline
\end{tabular}

IES: instituição de ensino superior. EPI: equipamentos de proteção individual. 
diminuir o tempo de rotatividade ${ }^{19}$, a ventilação ativa adicionada ao uso de máscaras faciais pode reduzir o risco de infecção individual, semelhante ao sistema anteriormente descrito ${ }^{22}$. Além de configurar uma medida de fácil implementação e de pouco custo, a manobra pode ser realizada com a simples abertura de janelas, como preconiza o protocolo do $\mathrm{MEC}^{15}$.

No tocante ao distanciamento entre os assentos em laboratório e cadeiras odontológicas em clínicas, sugere-se que seja necessário haver melhorias estruturais em algumas instituições de ensino. Neste quesito, as instituições privadas possuem maior flexibilidade de execução orçamentária e financeira, e este fato poderia contribuir para maior celeridade das reformas estruturais necessárias ${ }^{23}$. Neste sentido, o retorno das atividades práticas presenciais, em condições adequadas de funcionamento, possivelmente será iniciado nas instituições privadas e mais posteriormente nas públicas, em que os desafios relacionados à adequação da estrutura física são maiores ${ }^{24}$. Indiretamente, esta situação pode repercutir em maior tempo de retenção para os discentes das instituições públicas. Em um olhar mais aprofundado, deve-se refletir o quanto este fato pode interferir na vida daqueles que estudam em outros municípios, acarretando gastos com aluguel e vivendo longe de seus familiares, dificuldades já apontadas para a permanência no ensino superior brasileiro ${ }^{25}$.

Por isso, o replanejamento do espaço físico poderá se constituir de medidas mais simples, como o isolamento de bancadas em laboratórios e de unidades de atendimento em ambiente clínico, a fim de se garantir maior distanciamento entre os discentes e entre os pacientes. Estas medidas, por sua vez, já estão sendo adotadas em cursos que retornaram a partir da permissão de decretos locais $^{26}$. Além disso, estas manobras repercutirão em menor número de discentes em práticas e de pacientes em atendimento, porém são mais passíveis de serem alcançadas em curto prazo. Apesar de se esperar uma redução na quantidade de atendimentos ofertados nos cursos de Odontologia, considerando esse isolamento das unidades de atendimento, bem como o rodízio de discentes em aulas práticas, aponta-se para o aumento na procura por atendimento na reabertura das clínicas-escola de Odontologia. Isto porque, em decorrência da suspensão dos tratamentos odontológicos não emergenciais nos estabelecimentos da Atenção Primária à Saúde, recomendada pelo Ministério da Saúde, no início da pandemia, com ênfase para as urgências $^{27}$, projeta-se uma maior procura por tratamentos odontológicos eletivos, para atender a demanda de pacientes não tratados pelos serviços públicos e privados de saúde bucal durante a pandemia $^{28}$.

A redução na quantidade de pacientes atendidos nas clínicas de graduação pode trazer, indiretamente, outros dois impactos. Um relacionado à procura por cursos de pós-graduação lato sensu (especialização, aperfeiçoamento e atualização), aumentando os custos para uma boa formação clínica. $\mathrm{O}$ outro estaria relacionado à possibilidade de telemonitoramento, realizado conjuntamente por docentes e discentes a partir de tecnologias digitais, favorecendo o acompanhamento a distância dos pacientes ${ }^{29}$.

$O$ uso de EPI mais apropriados foi mencionado nas categorias de análise deste estudo. Diante das potencialidades das normativas sobre os EPI, destaca-se que a adoção de protocolos mais rígidos de biossegurança, com o intuito de impedir a disseminação do SARS-Cov-2. Paralelamente, reduzirá o risco de contaminação por outros patógenos e ampliará o cuidado contra outras infecções virais ${ }^{30}$. Entretanto, a aquisição dos EPI atualmente recomendados acarreta aumento de custos $^{31}$. Para as instituições de ensino, a compra desses insumos deverá atender às necessidades de professores e funcionários. Para os discentes, os EPI mais caros implicarão em maior 
comprometimento no orçamento individual ou familiar, principalmente para aqueles de baixa renda matriculados em instituições públicas ou para aqueles beneficiados por programas de financiamento estudantil que estão em instituições privadas.

A pandemia da COVID-19 está repercutindo também no aumento da produção de resíduo sólido hospitalar, principalmente pelo aumento significativo do uso e da troca de EPI, como as máscaras, luvas e roupas de proteção ${ }^{32}$. Como estes resíduos biomédicos podem levar à infecção indireta pelo vírus ${ }^{33}$, o manejo e descarte apropriados são extremamente importantes. Assim, é relevante considerar o aumento de custo, por parte das instituições, para a contratação de serviços especializados para os procedimentos de coleta e descarte adequados do lixo biológico ${ }^{34}$.

Como limitação deste estudo, destaca-se o fato de que as análises, frente ao cumprimento das normas de biossegurança relacionadas ao ensino odontológico, não foram extensivas aos campos dos estágios supervisionados, os quais se desenvolvem na rede de atenção à saúde, dentre outros espaços. Dessa forma, mais reflexões se fazem necessárias, considerando estes diferentes cenários, os quais são fundamentais e necessários para formação acadêmica em Odontologia.

Por fim, recomenda-se que as instituições de ensino em Odontologia não apenas elaborem ou adotem novos protocolos de biossegurança, mas também mobilizem discentes, docentes e funcionários para uma visão reflexiva das atividades práticas no contexto da pandemia, sensibilizando e instrumentalizando estes atores para o cumprimento cuidadoso e assíduo desses protocolos.

\section{CONCLUSÕES}

Uma série de mudanças precisam ser instituídas e cumpridas para que o retorno às atividades práticas no ensino odontológico ocorra de forma segura para discentes, docentes, funcionários e pacientes. A adoção de protocolos mais rígidos de biossegurança proporcionará, entre as principais potencialidades, a diminuição do risco biológico de transmissão de patógenos, ampliando o cuidado contra outras infecções, e a adequação de espaços físicos em ambientes de aprendizado mais ergonômicos. No que se refere às fragilidades, aponta-se o aumento de custo para os discentes e instituições e a redução no número de atendimentos.

As instituições públicas de ensino, possivelmente, enfrentarão dificuldades maiores para o retorno de suas atividades em comparação às privadas. Entretanto, existem desafios a serem considerados, por todas as instituições, no cumprimento dos novos protocolos de biossegurança no retorno das atividades práticas presenciais nos Cursos de Odontologia durante a pandemia da COVID-19.

\section{ABSTRACT \\ Dental education and the challenges related to complying with the new biosafety protocols in the COVID-19 pandemic context}

This study presents challenges related to the fulfillment of the new biosafety protocols aiming to return the face-to-face activities in higher education institutions in Dentistry considering the pandemic scenario of COVID-19. It was a qualitative, exploratory study, anchored in the technique of documentary research. We analyzed documents published by the Ministry of Education (MEC), the Federal Council of Dentistry (FCD) and the Brazilian Association for Dental Education (BADE). The documents were collected on websites of the selected entities. The treatment of qualitative data obtained was carried out by thematic content analysis to compare qualitatively the different documents by identifying convergent, divergent or absent points between them. From the 
problematization of the object under study, suggestions were made based on the weaknesses and potentialities related to the execution of the recommendations. Data were distributed in the analysis units "waiting room", "clinic" and "laboratory". The main potentialities were related to the reduction of the biological risk of transmission of pathogens and the adaptation of physical spaces in more ergonomic learning environments. As for the weaknesses, there are increased costs for students and institutions and reduced number of visits. There are challenges to be considered to comply with the new biosafety protocols in the return of practical activities in Dentistry Courses during the COVID-19 pandemic.

Descriptors: Coronavirus Infections. Containment of Biohazards. Infection Control, Dental. Education, Dental.

\section{REFERÊNCIAS}

1. Meng L, Hua F, Bian Z. Coronavirus disease 2019 (COVID-19): emerging and future challenges for dental and oral medicine. J Dent Res. 2020;99(5):481-87.

2. Zheng J. SARS-CoV-2: an emerging coronavirus that causes a global threat. Int $\mathrm{J}$ Biol Sci. 2020;16(10):1678-85.

3. World Health Organization (WHO). Virtual press conference on COVID-19 - 11 March 2020. [Acesso em: 3 out. 2020]. Disponível em: https://www.who.int/docs/defaultsource/coronaviruse/transcripts/who-audioemergencies-coronavirus-press-conferencefull-and-final-11mar2020.pdf?sfvrsn $=\mathrm{cb} 432 \mathrm{~b}$ b3 2.

4. World Health Organization (WHO). Coronavirus disease (COVID-19) pandemic. March 2021. [Acesso em: 2 mar. 2021]. Disponível em: https://www.who.int/emer gencies/diseases/novel-coronavirus-2019? gclid=Cj0KCQiA4feBBhC9ARIsABp_nbUo
bfRuZ9B8_lks0Dfh8nv0nIdcpGPbYE5P0VS mlyHye1ORYpiExc0aAlWNEALwwcB.

5. Nicola M, Alsafi Z, Sohrabi C, Kerwan A, Al-Jabir A, Iosifidis C, Agha M, Agha R. The socio-economic implications of the coronavirus pandemic (COVID-19): a review. Int J Surg. 2020;78:185-93.

6. Dias FA, Pereira ER, Silva RMCRA, Medeiros AYBBV. Public Health and the COVID-19 pandemic: challenges for global health. Res Soc Dev. 2020;9(7): e321974188.

7. Onyema EM, Nwafor CE, Obafemi, FA, Sen S, Atonye, FG, Sharma A, Alsayed AO. Impact of coronavirus pandemic on education. J Educ Pract. 2020;11(13):10821.

8. Sahu P. Closure of Universities Due to Coronavirus Disease 2019 (COVID-19): impact on education and mental health of students and academic staff. Cureus. 2020; 12(4):e7541.

9. United Nation (UN). Policy Brief: Education during COVID-19 and beyond. [Acesso em: 2 out. 2020]. Disponível em: https://unsdg.un.org/resources/policy-briefeducation-during-covid-19-and-beyond.

10. Brasil. Ministério da Educação. Portaria $n^{\mathbf{o}}$ 1.038, de 7 de Dezembro de 2020. Altera a Portaria MEC $\mathrm{n}^{\circ}$ 544, de 16 de junho de 2020, que dispõe sobre a substituição das aulas presenciais por aulas em meio digitais, enquanto durar a situação de pandemia do novo coronavírus - Covid-19, e a Portaria MEC $\mathrm{n}^{\circ} 1.030$, de $1^{\circ}$ de dezembro de 2020, que dispõe sobre o retorno às aulas presenciais e sobre caráter excepcional de utilização de recursos educacionais digitais para integralização da carga horária das atividades pedagógicas, enquanto durar a situação de pandemia do novo coronavírus Covid-19. Diário Oficial da União: seção 1, 
Brasília, DF, ano 2020, n.233-A. 07 dez. 2020. [Acesso em: 10 dez. 2020]. Disponível em: https://www.conjur.com.br/dl/portariamec-1038-aulas-presenciais.pdf.

11. Rashid S, Yadav S. Impact of Covid-19 Pandemic on Higher Education and Research. Ind J Hum Dev. 2020;14(2):3403.

12. Machado RA, Bonan PRF, Perez DEC, Martelli Júnior H. COVID-19 pandemic and the impact on dental education: discussing current and future perspectives. Braz Oral Res. 2020;34:e083.

13. Fernandez MDS, Silva NRJ, Viana VS, Oliveira CCC. Doença por Coronavírus 2019: desafios emergentes e o ensino odontológico brasileiro. Rev ABENO. 2020; 20(2):2-15.

14. Ghai S. Are dental schools adequately preparing dental students to face outbreaks of infectious diseases such as COVID-19? J Dent Educ. 2020;84(6):631-33.

15. Brasil. Ministério da educação. Secretaria de Educação profissional e tecnológica. Secretaria de educação Superior. Protocolo de biossegurança para retorno das atividades presenciais nas Instituições Federais de Ensino. [Acesso em: 27 set. 2020]. Disponível em: https://www.gov.br/mec/ptbr/centrais-de-conteudo/campanhas1/coronavirus/CARTILHAPROTOCOLOD EBIOSSEGURANAR101.pdf.

16. Conselho Federal de Odontologia (CFO). Manual de boas práticas em biossegurança para ambientes odontológicos. CFO: Brasília, 2020. [Acesso em: 31 ago. 2020]. Disponível em: https://website.cfo.org.br/ wpcontent/uploads/2020/04/cfo-lanc\%CC\% A7a-Manual-de-Boas-Pra\%CC\%81ticas-emBiosseguranc\%CC\%A7a-para-AmbientesOdontologicos.pdf.

17. Conselho Federal de Odontologia (CFO).
Recomendações AMIB/CFO para atendimento odontológico Covid-19: Comitê de Odontologia AMIB/CFO de enfrentamento ao COVID-19. Departamento de Odontologia AMIB - $2^{\mathrm{a}}$ Atualização 01/06/2020. 2020. [Acesso em: 31 ago. 2020]. Disponível em: https://website. cfo.org.br/wp-content/uploads/2020/06/ recomendacoes-amib-cfo-junho-2020.pdf.

18. Conselho Federal de Odontologia (CFO). Recomendações AMIB/CFO para atendimento odontológico Covid-19: Comitê de Odontologia AMIB/CFO de enfrentamento ao COVID-19. Departamento de Odontologia AMIB - $3^{a}$ Atualização 22/06/2020. 2020. [Acesso em: 31 ago. 2020]. Disponível em: https://website.cfo. org.br/wp-content/uploads/2020/06/ recomendacoes-amib-cfo-junho-2020.pdf.

19. Associação Brasileira de Ensino Odontológico (ABENO). Consenso ABENO: biossegurança no ensino odontológico pós-pandemia da COVID-19. 2020. [Acesso em: 2 set. 2020]. Disponível em: https://abeno.org.br/abeno-files/downlo ads/retomada-de-praticas-seguras-no-ensinoodontologico.pdf.

20. Deery C. The COVID-19 pandemic: implications for dental education. Evid Based Dent. 2020;21(2):46-7.

21. Iyer P, Aziz K, Ojcius DM. Impact of COVID-19 on dental education in the United States. J Dent Educ. 2020; 84 (6): 718-22.

22. Lelieveld J, Helleis F, Borrmann S, Cheng Y, Drewnick F, Haug G, Klimach T, Sciare J, Su H, Pöschl U. Model Calculations of Aerosol Transmission and Infection Risk of COVID-19 in Indoor Environments. Int $\mathbf{J}$ Environ Res Public Health. 2020;17 (21):8114.

23. Giacomoni J. Orçamento público. 17th ed. Revista e atualizada. São Paulo: Atlas; 2017. 
24. Peres KG, Reher P, Castro RD, Vieira AR. COVID-19-Related Challenges in Dental Education: experiences from Brazil, the USA, and Australia. Pesqui Bras Odontopediatria Clín Integr. 2020; 20(1):e0131.

25. Sorares LG. Desafios dos alunos de classes menos favorecidas para ingressar e permanecer na universidade. Rev Ext Cid. 2014;2(4):119-36.

26. Centro Educacional de Ensino Superior de Patos LTDA. Faculdades Integradas de Patos. Plano de Contingência da FIP Campina Grande frente à pandemia pelo SARS-COV-2 (COVID-19). Campina Grande; 2020.45p.

27. Brasil. Ministério da Saúde. CoordenaçãoGeral de Saúde Bucal. Departamento de Saúde da Família Secretaria de Atenção Primária à Saúde. Nota Técnica n 16/2020 CGSB/DESF/SAPS/MS. COVID-19 e atendimento odontológico no SUS. 2020. [Acesso em: 28 dez. 2020]. Disponível em: http://www.crosp.org.br/uploads/arquivo/29 5c9c14409db20cb63c862bb07ce0e4.pdf.

28. Moraes RR, Correa MB, Queiroz AB, Daneris Â, Lopes JP, Pereira-Cenci T, D'Avila OP, Cenci MS, Lima GS, Demarco FF. COVID-19 challenges to dentistry in the new pandemic epicenter: Brazil. PLoS One. 2020;15(11):e0242251.

29. Conselho Federal de Odontologia (CFO). Resolução CFO-226, de 04 de junho de 2020. Dispõe sobre o exercício da Odontologia a distância, mediado por tecnologias, e dá outras providências. [Acesso em: 12 mar. 2020]. Disponível em: http://sistemas.cfo.org.br/visualizar/atos/RE SOLU\%C3\%87\%C3\%83O/SEC/2020/226.
30. Bartoszko JJ, Farooqi MAM, Alhazzani W, Loeb M. Medical masks vs N95 respirators for preventing COVID-19 in healthcare workers: A systematic review and metaanalysis of randomized trials. Influenza Other Respir Viruses. 2020;14(4):365-73.

31. Cavalcanti YW, Silva RO, Ferreira LF, Lucena EHG, Souza AMLB, Cavalcante DFB et al. Economic Impact of New Biosafety Recommendations for Dental Clinical Practice During COVID-19 Pandemic. Pesqui Bras Odontopediatria Clín Integr. 2020;20(1):e0133.

32. Kampf G, Todt D, Pfaender S, Steinmann E. Persistence of coronaviruses on inanimate surfaces and their inactivation with biocidal agents. J Hospital Infect. 2020;104(3):24651.

33. Rhee SW. Management of used personal protective equipment and wastes related to COVID-19 in South Korea. Waste Manag Res. 2020;38(8):820-824.

34. Costa LN, França AAC, França PSS, Borges JA, Madureira HP, Maciel RF. COVID-19: o isolamento social e a geração de resíduos sólidos na cidade de São Luís-MA. HOLOS. 2020;5:1-11.

\section{Correspondência para:}

Suyene de Oliveira Paredes

e-mail: suyparedes@hotmail.com

Rua Evangelina Rodrigues de Sousa, $\mathrm{n}^{\circ} 15$.

Bairro Maternidade

58701-323 Patos/PB 